\title{
MAPPING PERCEIVED SOCIO-EMOTIVE QUALITY OF SMALL-GROUP FUNCTIONING
}

\section{$\underline{\text { Herman Buelens }}$}

Affiliation: K.U.Leuven, Educational Support Office / Information and Communication Technology in Education

Address: Naamsestraat 98, B-3000 Leuven, Belgium

Phone: +32 (0)16 326560

Fax: +32(0)16326542

Email: Herman.Buelens@duo.kuleuven.ac.be

\section{$\underline{\text { Jan Van Mierlo }}$}

Affiliation: K.U.Leuven, CEPO, Department of Communication Address: Van Eventstraat 2A, B-3000 Leuven, Belgium

Phone: +32 (0)16 323217

Fax: +32 (0)16323 312

Email: Jan.VanMierlo@soc.kuleuven.ac.be

$\underline{\text { Jan Van den Bulck }}$

Affiliation: K.U.Leuven, CEPO, Department of Communication Address: Van Eventstraat 2A, B-3000 Leuven, Belgium

Phone: +32 (0)16 323294

Fax: +32 (0)16323 312

Email: Jan.VandenBulck@soc.kuleuven.ac.be 
Affiliation: K.U.Leuven, Educational Support Office / Information and Communication Technology in Education

Address: Naamsestraat 98, B-3000 Leuven, Belgium

Phone: +32 (0)16 326549

Fax: +32 (0)16 326542

Email: Jan.Elen@duo.kuleuven.ac.be

\section{$\underline{\text { Eddy Van Avermaet }}$}

Affiliation: K.U.Leuven, Laboratory for Experimental Social Psychology, Department of Psychology

Address: Tiensestraat 102, B-3000 Leuven, Belgium

Phone: +32 (0)16 326098

Fax: +32 (0)16 325923

Email: Eddy.VanAvermaet@psy.kuleuven.ac.be 


\title{
MAPPING PERCEIVED SOCIO-EMOTIVE QUALITY OF SMALL-GROUP FUNCTIONING
}

\begin{abstract}
This chapter demonstrates the influence of the socio-emotional quality of small-group functioning in a collaborative learning setting.

It reports a case study from a sophomores' class at a Belgian university. The subjects were 142 undergraduates sub-divided into 12 project-groups of 12 students each. Following a description of the collaborative learning setting, a longitudinal survey study focusing upon the evolution of the learners' perception of their own group’s socio-emotional functioning is presented.

The aims of the study were to map group member's perception of the socio-emotive quality of their own group functioning and to examine if and how problems in groups of learners can be detected as soon as possible. Having demonstrated that dysfunctionalities within groups can be detected rather early, the authors hope that corrective interventions can be implemented when they can still have an effect.
\end{abstract}




\section{INTRODUCTION}

Students who collaborate in small groups on a common research project have abundant opportunities to present and discuss ideas as well as to plan, organize and carry out activities related to the task at hand. Several authors attribute a long list of potential benefits to the richness and the diversity of these learner activities. Because a collaborative learning environment involves students actively in the learning process, educational theorists believe that collaborative settings such as small project groups of co-learners are an effective means of learning, and they therefore play and important role in knowledge construction (Blumenfeld et al., 1996; Collins et al., 1989). By expressing ideas into words, by formulating opinions, by externalizing tacit knowledge, attitudes, approaches, values and perspectives, learners are expected to explore in more detail their own understanding (Johnson, 1971, 1974), to generate more and better questions (Panitz, no date) and to develop higher level thinking skills (Johnson, 1971; Vygotsky, 1978). It is hoped that vague mental conceptualizations of an idea become internalized into more concrete representations (Resnick, et al., 1991) resulting in a long-lasting, firmly rooted understanding (Kulik \& Kulik 1979). Because cognitive activities of learners become visible during group work, these activities also become subject to intervention and coaching. Hence, the externalized ideas of the learner provide a means for other learners and their teachers to react to, negotiate around, and build upon what they heard from the learner's side (Arias et al., 1999). Consequently, the conceptualizations of co-learners will gradually become fine-tuned and a common language and a common understanding -or a 'shared knowledge'- will be created (Scardamalia \& Bereiter, 1994). Important as they are, the cognitive benefits listed above are but a small portion of the advantages attributed to collaborative learning. Panitz (no date) for example presents a referenced list of 67 
theoretical advantages of collaborative learning, ranging from academic over social to psychological and assessment benefits. Not unimportantly, some of the cognitive benefits believed to be associated with collaborative learning have already received direct empirical support. To illustrate, two recent reviews are positive with regard to the effectiveness of various forms of small group learning. Springer et al. Should be all names (1999) conclude that small-group learning is successful in promoting greater academic achievement and more favorable attitudes toward learning. According to the authors, these results are superior to most findings in comparable reviews of research on other educational innovations. Comparing small group and individual learning in a context in which students learn to use computer technology, Lou et al. All names (2001) found significant positive effects of small group learning on student individual achievement, task performance and several process and affective outcomes. In view of the overwhelming number of theoretical arguments and of the empirical support for the cognitive benefits associated with collaborative learning, it would therefore appear as if there is every reason to promote collaborative instructional formats.

However, this enthusiasm regarding collaborative work environments is not shared by everyone. Diehl \& Stroebe $(1987 ; 1991)$ for example notice that several forms of 'cognitive blocking' can hinder the cognitive processes of individuals, and mainly so during face-to-face synchronous communication sessions within a group. While brainstorming, some group members are talking too fast for others to react upon, theses are remembered imprecisely or they are quoted incorrectly, irrelevant or long meandering monologues enter group discussions, etc. These interactions interfere with, and disrupt ongoing cognitive processes, thereby thwarting the learning outcomes intended by having students communicate with each other. 
Aside from cognitive blocking effects, which are perhaps only detrimental with regard to individual learning outcomes in the short run, more serious and longer lasting negative effects of group work have also been described. Bales (1953) noticed that instrumental, task-related activities within a group of co-acting people cannot be considered apart from the socio-emotive context in which these activities take place. In the same vein, others have pointed out that collaborative work can have but little effect on students' learning outcomes, because teams (of collaborating learners) can fall prone to a long list of social inhibiting factors which impede participants from performing effectively (McGrath, 1984; Salomon, \& Globerson, 1989; Hertz-Lazarowitz et al., 1992; Paulus, 2000; Paulus et al., 2002; Brown, 2000). 'Social inhibition’ can result from group members’ tendency to make self-favoring social comparisons by contrasting their own contributions with those of (somewhat) less performant group members (i.e. “downward comparison”). The resulting belief that one is doing quite well (an 'illusion of productivity') may further inhibit the efforts exerted by group members (Paulus, 2000, p. 242). In the worst case, the vicious circle of downward social comparison might be consolidated in a group norm prescribing low achievement. Most attention however has been paid to the empirically sound observation that group members reduce or 'inhibit' individual effort, when their contributions to a common group task remain unidentifiable (i.e. "social loafing” and "free riding’; e.g. Williams, Harkins \& Latané, 1981). Of course, individual group members who refrain from taking responsibility in fulfilling their part of the work slow down project work itself. More detrimental however is their long-term effect upon both socio-emotional group life and upon the development of trust between group members. This is particularly regrettable, because both intra-group socio-emotional stability and trust are important antecedent conditions for group members to learn from and with each other (Bruffee, 1994). It therefore seems as if the potential benefits associated with small group projects 
will be a function of the group’s capability not only to cope with task-related aspects, but also to develop and to maintain a constructive socio-emotive group life.

From a teacher's point of view, the question arises - how to coach a group of collaborative learners adequately? Successive preventive, diagnostic and curative actions might be considered. As an initial 'preventive' step, teachers can try and design the collaborative environment such that the opportunities for a group to deal successfully with both task relevant and socio-emotional aspects of group life are maximized. A deliberately designed collaborative environment however does not guarantee that all groups will do well. Therefore, teachers need a subsequent (second) evaluative phase in which groups that go astray will be detected. Although both are necessary, the follow-up of task related group activities is a notably easier job than adequately scrutinizing socio-emotional and intragroup relational patterns.

The difficulty of monitoring socio-emotional aspects of group life is at the heart of a case study from a sophomores” class at a Belgian university (the “media studies seminar (MSS)” presented hereafter. First the seminar itself will be introduced and some attention will be given to elements of the design that were explicitly incorporated in order to help groups deal successfully with both task relevant and socio-emotional aspects of group life (cf. the 'preventive' step). Next, a longitudinal survey focusing upon the evolution of the learners' perception of their own group’s socio-emotional functioning will be presented. The aims of the study were to map group members' perception of the socio-emotive quality of their own group functioning and to examine if and how problems emerging in a (partly face-to-face, partly virtual) group of learners can be detected as soon as possible (cf. the 'diagnostic' step). 
In the present study, no attempt was made to proceed to the 'curative' step based on the data gathered. Groups were thoroughly coached as usual, but the coaches were not informed about the survey-data. The aim was to map the spontaneous evolution of the perceived quality of group functioning in a context where coaches cannot but count upon their experience and devotion to optimize in-group activity. It will be clear however that in the future, survey data will be put at the disposal of both the coaches and the groups, if it would turn out that this 'diagnostic' information might constitute a useful instrument to guide 'curative' interventions.

\section{THE MEDIA STUDIES SEMINAR}

The MSS is one of the ten courses students have to take in the second year of the undergraduate communication sciences programme at the largest Belgian university (K.U.Leuvenfull title of university). The MSS takes the format of an ICT supported business simulation covering the full academic year. It aims are to make students familiar with empirical research in communication sciences. Students have to acquire the basic skills necessary to investigate a new problem within this science discipline independently and they have to be able to deliver a final report of good quality. At the start of the seminar, students can indicate which of the (about 15) available research topics they would like to work on (e.g., how do parents coach children in their media use; romance, relationships and sexuality in popular TV-shows; the meaning of media for the visually impaired, etc.). Taking into account their personal preference, (about 10) students with common interests are put together into the same project groups and they will work together at the project during the full academic year. Since they have already spent one year 
together, most students will know each other. Typically, students within a project group met several times a week, each time for a period ranging from a few minutes up to several hours.

At the start of the project, each project group has to submit a research proposal in the form of a detailed business tender (including a time schedule, a budget and staffing plan). Following the approval of the business tender by the team of project coaches, each project group is subdivided into four smaller units. Every unit holds the main responsibility for group work during one of the four major stages of the MSS. In a first stage, students explore the available literature on the subject and a central research question is derived. In a second phase, students construct a research instrument (e.g., a survey, a tool to analyze newspaper-content). In a third stage, the actual research is carried out (e.g. interviewing people, analyzing content, conducting a telephone survey) after which the data collected are analyzed. In a final stage, a research report is written and all the project groups present their own project to the other groups during a simulated academic conference. The latter activity concludes the business simulation.

Since the MSS was the first experience of these students with both empirical research and collaborative group work at the university, great efforts were made to help them to have a fruitful learning experience. First, attractive, professionally relevant, socially meaningful and motivating research topics were presented (see the examples above). In addition, students were asked to apply for a specific topic. As a result, student motivation was enhanced, complaints about unfair allocation of topics were avoided and, perhaps most importantly, students knew that other group members would also be interested in the topic. 
Second, great care was taken that groups could start work as soon as possible. Therefore, all groups were provided with a written rationale covering all the stages of the group work. In a first collective meeting, this rationale was explained in detail. It was explicated why collaborative group work is required for this project and what learning outcomes it was hoped would be achieved. Deadlines and formal requirements were indicated. It was made clear how group work and individual contributions would be assessed (i.e. all subjects within a group will receive the same mark that can be slightly corrected by means of a peer assessment procedure). Hints and helpful resources were added. It was explained what to do if the group had difficulties, what the potential risks of group work are and how to deal with them. An overview of when and where to meet with the teachers was included. Third, by partitioning group work into mutually connected sub-tasks, and by advising about role and turn taking within subgroups, the stage was set to create a fair division of labor, to install a relative high degree of positive interdependence, as well as to keep the whole project manageable for the students. Fourth, to enhance individual accountability and responsibility the task was subdivided in smaller units, and each student's contribution within the group was assessed by their peers at four points during the academic year. Fifth, group project work was sustained on a continuous basis by means of a Digital Learning Environment (DLE). Functionalities that enhance information delivery and information exchange between learners (such as digital drop boxes, group pages and group calendars) were promoted when it came to writing reports and planning group activities. The use of asynchronous communication tools (such as group e-mail and group discussion fora) was encouraged to prepare (and follow up) regular face-to-face meetings. Besides facilitating group work in a direct way, having a virtual group space at one's disposal was also intended to enhance a feeling of belonging to a group. Via the promotion of the use of asynchronous communication tools, teachers hoped to provide opportunities for students to 
collaborate in ways that lead to shared understanding (e.g. Brown, 1990; Hiltz, 1990; Harasim, 1990) and they hoped to prevent several forms of 'cognitive blocking' (cf. supra). Finally, a great deal of monitoring and coaching moments were embedded in the design of the MSS. At designated times relatively informal meetings were organized with each group, and individual group members were free to contact their teachers at all times. On more formal occasions small oral presentations including a report of group progress were scheduled. As indicated earlier, group members had to assess the contribution of each group member. These peer-evaluation data were also used by teachers as a monitoring tool.

However, despite all the preventive measures taken, year after year it turned out that about one third of the groups suffered from an inferior socio-emotional atmosphere. Moreover, despite attempts to monitor groups closely, instructors found it hard to judge the socioemotive aspect of group functioning correctly. After all, instructors always remain relative outsiders. In addition, groups of learners remained highly reluctant to report emerging problems in their group, partly perhaps, because they worried about losing marks if teachers discovered that a group was confronted with difficulties that could not be solved by the group itself. Only at the end of the academic year did some individual students started complaining about how their group had been or was doing. At that late stage, teachers ran the risk of misjudging the complaint. Moreover, even when a correct diagnosis of the complaint would have been possible, no time was left for curative actions to be implemented.

Therefore, at the beginning of the academic year 2001-2002, we started investigating if and to what extent relational group (dys) functioning can be mapped at the very early stages of group work by means of an ad hoc constructed measurement tool. This diagnostic 
instrument described below, is a rather broad-spectrum questionnaire reflecting socioemotional aspects of group membership as well as perceptions, evaluations and feelings about the group as a whole, its members, and the student's own membership within the group. By administering the (online) questionnaire to group members at set times it is our aim to obtain an evolutionary diagnostic group-profile.

\section{MAPPING PERCEIVED SOCIO-EMOTIVE QUALITY OF GROUP FUNCTIONING}

In this section, first the measurement tool and the data collection process will be highlighted. Next, we will turn to a report and an analysis of the results obtained.

\section{Measurement Tool And Data Collection}

During the academic year 2001-2002, the MSS was attended by 142 second year communication science undergraduates at the K.U.Leuven. Taking into account their own preference, 12 different project groups of 12 students each were formed. Each project group was subdivided into four sub-units of three students each. Every 1.5 months (November 2001, February 2002, March 2002, May 2002), following the completion of each major stage of the MSS, an online questionnaire (81 items) was administered to all 142 students. The questionnaire related to the project group as a whole ${ }^{\mathrm{i}}$ (12 students) and it comprised 10 existing scales measuring different aspects of the quality of group functioning: 'Interaction’ (Watson et al., 1991; 8 items), 'Equal Contribution’ (Kramer et al., 1997; 11 items), 'Discussion Quality’ (Kramer et al., 1997; 3 items), 'Dominance' (Kramer et al., 1997; 2 items), 'Solidarity' (Wheeles et al., 1982; 13 items), 'Affect' (Freeman et al., 1996; 6 items), 'Fairness of Equal Scores' (Freeman et al., 1996; 2 items), 
'Fairness of Contribution’ (Freeman et al., 1996; 3 items), 'Waste of Time’ (Freeman et al., 1996; 3 items), 'Surplus Value of Group Work’ (Freeman et al., 1996; 6 items), together with some items that were constructed to indicate 'Illusion of Productivity (5 items)', 'Free Riding (4 items)', 'Downward Comparison (4 items)' and 'Within group communication (11 items)'

A few examples of questions are: 'I am satisfied with how group members interact with each other'; 'I feel we have good communication among group members’; 'Every member of our group deserves the same final grade’. All 81 items were scored on a common sixpoint scale (1=strongly disagree; 6=strongly agree). Since the questionnaire was completed four times by each of the 142 subjects, a data-matrix consisting of 142 subjects by 4 measurements by 81 items was obtained.

\section{Analysis \& Results}

\section{Socio Emotive Quality of Group Functioning}

The data-matrix was restructured in a two-way table consisting of 568 rows (142 students * 4 measurements) and 81 columns (scores on 81 items). To detect like patterns of socio emotive quality of group functioning (i.e. data within one row) a cluster analysis (Ward's method; squared Euclidian distances) was performed on the rows of the two-way table. The analysis clearly categorizes perceptions of students (at a set moment) in two distinct clusters. One 'cluster' or 'class' consists of those students who indicated their group was doing well during the preceding 1.5 month (the 'functional' cluster). A second 'cluster' contains those students who indicated that they were rather dissatisfied with their group and the way it was functioning during the preceding 1.5 month (the 'dysfunctional' cluster). Students in the 'functional' cluster perceived their group as a coherent and 
harmonious entity and indicated that they performed more efficiently than if there were no groups (during the preceding 1.5 month). They believed that their interactions resulted in decisions of good quality. Group-work was not perceived as a waste of time and students were satisfied with both the final result of the group work and with the way group members interacted with each other. Students had the perception that all group members contributed evenly, that there were no distinctly dominant group members nor free-riders. They judged it as fair that everyone in their group would receive the same score. Students in the 'dysfunctional' cluster show the reverse pattern.

Next, for each of the four periods preceding a measurement, the relative number of students in the 'functional' cluster was used as an index of the perceived quality of socioemotive quality of a group during that period. As it turned out, some groups consist exclusively of subjects from the 'functional' cluster (see Figure 1: group 1 before November 2001), while other groups consist only of students from the 'dysfunctional' cluster (see Figure 1: group 3 before November 2001). Clearly, the socio-emotive quality within such a group is very low. Furthermore, Figure 1 clearly shows that by and large the 'perceived quality of group functioning' remained constant over the academic year. Groups that did not score well after the first stage of the project (November 2001) generally were classified as 'dysfunctional' after completion of the other three stages as well. Similarly, groups that started well remained 'functional' during the remainder of the project. That is not to say that no changes at all were observed. As can be seen in Figure 1, the most marked changes in socio-emotive quality of group functioning (group 1 and group 7) are noticed between the first (November 2001) and the second (February 2002) measurement. 
Figure 1 about here

\section{Relation Between Socio-Emotive Quality Of Group Functioning And 'Getting On}

\section{With The Job'}

At the end of the academic year, the final reports of the groups were graded by the faculty member responsible for the MSS in consultation with the groups' instructors. It is interesting to observe that the two 'dysfunctional' groups (group 3 and group 10) were the only groups failing to score higher then 10 on a 20 point scale. On the other hand, the most functional groups scored best on their final report. This important result challenged us to look into the relationship between the socio-emotional and the task related aspects of group functioning. As indicated above (Bales, 1953), getting on with the job and getting on with other people within the group seems essential for delivering a good final group result. The correlation between both was investigated. The final grade on the seminar group's reports was taken as an index of successfully coping with the job. For 'getting on with people', it was assumed that the percentages of group members who belonged to the functional cluster were an adequate measurement unit. A Spearman Correlation between both scores showed a substantial relationship between 'getting on with the job' and 'getting on with your fellow team members'. The correlation was $r=0.7, p<0.0001$. Project groups with a lot of students in the dysfunctional cluster (groups scoring low on 'getting on with people'), consequently do not score as well for their final report as groups in which more students say that their group is functional. 


\section{Academic Achievement}

One obvious factor, which might moderate the observed relationship between socioemotional and task-related aspects of group functioning, is the student's level of academic achievement. Students' result, at the end of their first undergraduate year, was taken as an index of academic achievement. In order to test the potentially moderating role of ‘academic achievement', a repeated measurement ANOVA ${ }^{\text {ii }}$ This will not show up on paperwas performed, using the subjects' academic achievement as a covariate, and with the four different moments of measurement as a within subjects or time factor (socioemotional functioning) and group membership as a between subjects factor (having 12 levels). The within subjects or time factor was not at all significant $(F(2.44,290.18)=$ 0.96), indicating that --as expected-- there were no differences between the indices at the four different moments. More important, the covariate academic achievement also did not reach any significance level $(F(1,119)=0.65)$. This confirms our thesis that the differences in socio-emotional indices between the groups cannot be attributed to differences in overall academic achievements between these groups. The between subjects factor of group functioning, however, was highly significant $(F(11,119)=6.52, p<.001)$, which is clearly illustrated in Figure 2. The estimated marginal means of the socioemotional indices are clearly different between the 12 groups. Yet, most of them are situated between 0 and 5. Furthermore, there was a significant interaction between group functioning and the repeated measures time factor $(F(26.82,290.18)=4.10, p<.001)$. When inspecting the figure, it can be seen that there is a great deal of variation in the fluctuations of the curves between the 12 groups. In our opinion, this interaction should not be over-interpreted. There are no clear patterns of differences between groups of either increased or decreased estimated marginal means over time. There are differences and crossings between curves, but for all groups, the estimated means remain at the same level 
in a rather horizontal manner. (The repeated measures or time factor was not at all significant).

Summarizing, we feel that the differences in the groups' socio-emotional functioning are not influenced by the overall academic achievement of the members of these groups.

Figure 2 about here

\section{DISCUSSION}

Bringing about successful group work is not just a matter of putting students together. Students do not automatically become involved, thoughtful, tolerant, cooperative or responsible when working with others. The ultimate learning effect of group work depends on what the tasks are, how the group is organized, who participates, and how the group is held accountable. Teachers must consider these factors in designing group work and they must address potential problems of process if group work is to be successful. However, explaining the task and guiding the groups through their project etc. do not, by themselves seem to give any guarantee for a successful project. In this chapter, it was demonstrated that in collaborative learning there is also a clear influence of the socioemotional quality of group functioning.

\section{Findings}

"Stability" 
One of the most astonishing results of our research is that by and large the 'perceived quality of group functioning' remained constant over the academic year. Groups that did not score well after the first stage of the project generally were classified as 'dysfunctional' after completion of the other three stages as well. Similarly, groups that started well, remained 'functional' during the rest of the project (cf. Figure 1). However, and against this general trend, some (relatively small) variations in socio-emotional quality were observed going from the first (November 2001) to the second (February 2002) measurement. In the language of group-development theories, perhaps groups are leaving (see figure 1, group 7) or entering (see figure 1, group 1) the 'storming stage’ in which conflict is the general theme and in which task resistance (such as missed meetings or reduced task focus) and relationship hostility between group members are common (Tuckman \& Jensen, 1977).

\section{“Applicable Instrument”}

Having demonstrated that dysfunctional groups can be detected rather early using a questionnaire that measures different aspects of group functioning, an optimistic perspective is being offered here. Interventions can be planned at a time when they can still have an effect. Moreover, our rather elaborate questionnaire and the resulting group profile offer a first diagnosis of the (dys) functionality within a specific group.

Pending a more detailed analysis of the dysfunctions observed, simple feedback from the teacher, a group discussion, coaching, and pre-training for cooperation (listening and resolving conflicts; learning to appreciate skills and abilities of group members) constitute examples of potentially useful intervention strategies. 


\section{Future Research}

Based on our research, which indicates that dysfunctional groups can already be detected at a very early stage of group functioning, we suggested that interventions should also begin early in the process. Although it can be argued that early interventions stand a better chance of being successful than late interventions, in view of the stability findings we don't know however whether interventions will have an effect at all. Is there really a way to overcome these primacy effects and these stability effects? Moreover, there are different ways for a teacher to intervene in dysfunctional groups. Is simple feedback based on the questionnaire data collected enough, or will more radical coaching or collaborative skills training be necessary? Future research may give us some indication. Also, further research is needed at the level of the task analysis. There seems to be a serious shortage of models of task analysis in collaborative learning. Finally, our admittedly superficial analysis of the relationship between the socio-emotional functioning of project groups, their 'ability' and the groups' results, should be supplemented by a more fine grain analysis.

\section{Limitations And Conclusions Of The Study}

This study obviously has a number of limitations. First, it is important to note that this chapter deals with rather large groups (12 people) of peers working together in a research seminar in media training. Although many of the factors involved may be exclusively ingroup factors, it is obvious that factors external to the group can also be at work and have an impact on behavior inside the group. Furthermore, some of our participants may have had previously shared experiences, as they had studied together in their first undergraduate year. In addition, the students' motivation to participate in 'collaboration' is partly extrinsic. Group work is not an option it is a course requirement. Moreover, the setting of the students' collaboration is itself a potential intervening factor. Working together has 
become an important aspect of student life at our university. Students work together not only in study surroundings, but also in more informal surroundings such as e.g. students' residences. It can therefore be argued that the impact of the collaborative learning present in our research may differ from the impact of the setting for other forms of collaborative learning.

In addition, our research deals with very diverse forms of in-group communication. Part of the subjects' communication is asynchronous computer-mediated communication using the DLE part is face-to-face communication. Project groups differ in their relative use of these two modes of communication. We noticed that some groups made almost no use the DLE options. Other groups preferred to discuss their research using nothing but the DLE. The potential influence of the different communication modes was not studied in this chapter, but it provides an interesting topic for future research.

As a final limitation, although we monitored the subjects' socio-emotional functioning for nearly eight months, due to the length of this period it was almost impossible to deal with every possible factor that may have influenced the socio- emotional relations in the different project groups.

The goal of this chapter was not to argue for any particular view of the best prototypical scenario for group learning. If anything, our research made us aware of the vast differences that can be observed between collaborative settings. This is important, because what counts as collaboration within a group will differ widely. To our knowledge there is still no agreed upon framework to compare and to contrast studies on collaborative learning. It is our firm conviction, based on our findings, that task related factors and socio-emotional factors should both occupy a place in this framework. 


\section{ACKNOWLEDGEMENTS}

The authors express their sincere appreciation to Jos Feys and Martine Beullens for their statistical advice. 


\section{FOOTNOTES}

\footnotetext{
${ }^{\mathrm{i}}$ The functioning of the smaller units of three is not the focus of this chapter. Even though a separate questionnaire for measuring the functioning of these units was used, we will not present the conclusions here. ${ }^{\mathrm{ii}}$ The Greenhouse-Geisser epsilon was .81, which is greater than the .75 criterion proposed by Stevens (1986; cfr. Hatcher \& Stepansky, 1994, p. 237), there was no need to switch to a MANOVA. For the averaged tests of significance, this epsilon was used to adjust the degrees of freedom.
} 


\section{REFERENCES}

Arias, E.G., Eden, H., Fischer, G., Gorman, A., \& Scharff, E. (1999). Beyond access:

Informed participation and empowerment. In C. Hoadley \& J. Roschelle (Eds.)

Proceedings of the Computer Support for Collaborative Learning (CSCL) Conference, Dec

12-15, Stanford University, Palo Alto, California. NJ: Lawrence Erlbaum Associates.

Bales, R.F. (1953). The equilibrium problem in small groups. In: T. Parsons, R.F. Bales \&

E.A. Shils (Eds.), Working papers in the theory of action. New York: Free Press.

Blumenfeld, P.C., Marx, R.W., Soloway, E., \& Krajcik, J. (1996). Learning with peers:

From small group cooperation to collaborative communities. Educational Researcher, 24

(11), 37-40.

Brown, J. (1990). Towards a new epistemology for learning. In C. Frasson \& J. Gauthiar,

J. (Eds.), Intelligent Tutoring Systems: At the crossroads of artificial intelligence and education, NJ Ablex.

Brown, R. (2000). Group Processes. Dynamics within and between groups ( $2^{\text {nd }}$ Ed.)

Oxford: Blackwell Publishers.

Bruffee, K. A. (1994). The art of collaborative learning: Making the most of knowledgeable peers. Change, 26(3), 39-44.

Collins A., Brown, S.J., \& Newman, S.E. (1989). Cognitive apprenticeship: Teaching the craft of reading, writing and mathematics. In L.B. Resnick (Ed.), Knowing, learning, and instruction. Essays in honor of Robert Glaser. (pp. 453-494). Hillsdale, NJ: Lawrence Erlbaum.

Diehl, M., \& Stroebe, W. (1987). Productivity loss in brainstorming groups: Toward the sollution of a riddle. Journal of Personality and Social Psychology, 53, 497-509. 
Diehl, M., \& Stroebe, W. (1991). Productivity loss in idea-generating groups: Tracking down the blocking effect. Journal of Personality and Social Psychology, 61, 392-403. Freeman, K.A. (1996). Attitudes toward work in project groups as predictors of academic performance. Small Group Research, 27 (2), 265-282.

Harasim, L. (Ed.) (1990). Online education: Perspectives on a new environment. New York: Praeger.

Hertz-Lazarowitz, R., Beneviste Kirkus, V., \& Miller, N. (1992). Implications of current research on coooperative interaction for classrooom application. In R. Hertz-Lazarowitz \& N. Miller (Eds.), Interactions in cooperative groups. The theoretical anatomy of group learning (pp. 253-280). Cambridge: Cambridge University Press.

Hiltz, S. (1990). Evaluating the virtual classroom. In L. Harasim, (Ed.) Online education: Perspectives on a new environment. New York: Praeger, (pp.134-183).

Johnson, D. W. (1971). Effectiveness of role reversal:actor or listener, Psychological Reports, 28, 275-282.

Johnson, D. W. (1973). Communication in conflict situations: A critical review of the research, International Journal of Group Tensions, 3, 46-67.

Johnson, D. W. (1974). Communication and the inducement of cooperative behavior in conflicts: A critical review, Speech Monographs 41, 64-78.

Kramer, M.W., Kuo, C.L., \& Dailey, J.C. (1997). The impact of brainstorming techniques on subsequent group processes: Beyond generating ideas. Small Group Research, 28, 218242.

Kulik, J.A., \& Kulik, C.L. (1979), College teaching. In: Peterson and Walberg (Eds.) Research in teaching: Concepts, findings and implications, Berkeley, CA: McCutcheon Publishing. 
Lou, Y. Abrami, C.A., Spence, J.C., Poulsen, C., Chambers, B., \& d’Apollonia, S. (1996). Within-class grouping: A meta-analysis. Review of educational research, 66, 423-458. Lou, Y., Abrami, P.C., \& d'Apollonia, S. (2001). Small group and individual learning with technology: a meta-analysis. Review of Educational Research, 71 (3), 449-521. McGrath, J.E. (1984). Groups, interaction, and performance. Englewood Cliffs, NJ: Prentice-Hall.

Panitz, T. (no date). The case for student centered instruction via collaborative learning paradigms. http://home.capecod.net/ tpanitz/tedsarticles/coopbenefits.htm.

Paulus, P.B. (2000). Groups, teams and creativity: the creative potential of idea-generating groups. Applied Psychology: An International Review, 49(2), 237-262.

Paulus, P.B., Dugosh, K.L., Dzindolet, M.T., Coskun, H., \& Putman, V.L. (2002). Social and cognitive influences in group brainstorming: Predicting production gains and losses. In: W. Stroebe \& M. Hewstone (1991). European Review of Social Psychology, 12, 299325.

Resnick, L.B., Levine, J.M., \& Teasley, S.D. (Eds.) (1991). Perspectives on socially shared cognition. American Psychological Association, Washington, D.C.

Salomon, G. \& Globerson, T. (1989). When teams not function the way they ought to. International Journal of Educational Research, 57(2), 149-174.

Scardamalia, M. \& Bereiter, C. (1994). Computer support for knowledge-building communities. Journal of the Learning Sciences 3(3), 265-283.

Springer, L., Stanne, M.E. \& Donovan, S.S. (1999). Effects of small-group learning on undergraduates in science, mathematics, engineering, and technology: A meta-analysis. Review of Educational Research, 69(1), 21-51.

Stevens, J. (1986). Applied multivariate statistics for the social sciences. Hillsdale, N.J.: Lawrence Erlbaum Associates. 
Tuckman, B. W., \& Jensen, M. A. (1977). Stages of small group development revisited. Group and Organizational Studies, 2 (4), 419-427.

Vygotsky, L.S. (1978) Mind in society. Cambridge.

Wheeless, L.R., Wheeless, V.E., \& Dickson-Markman, F. (1982). A research note: The relations among social and task perceptions in small groups. Small Group Behavior, 13 (3), 373-384.

Williams, K., Harkins, S. \& Latané, B. (1981). Identifiability as a deterrent to social loafing: Two cheering experiments. Journal of Experimental Social Psychology, 40,303311. 


\section{FIGURE 1}
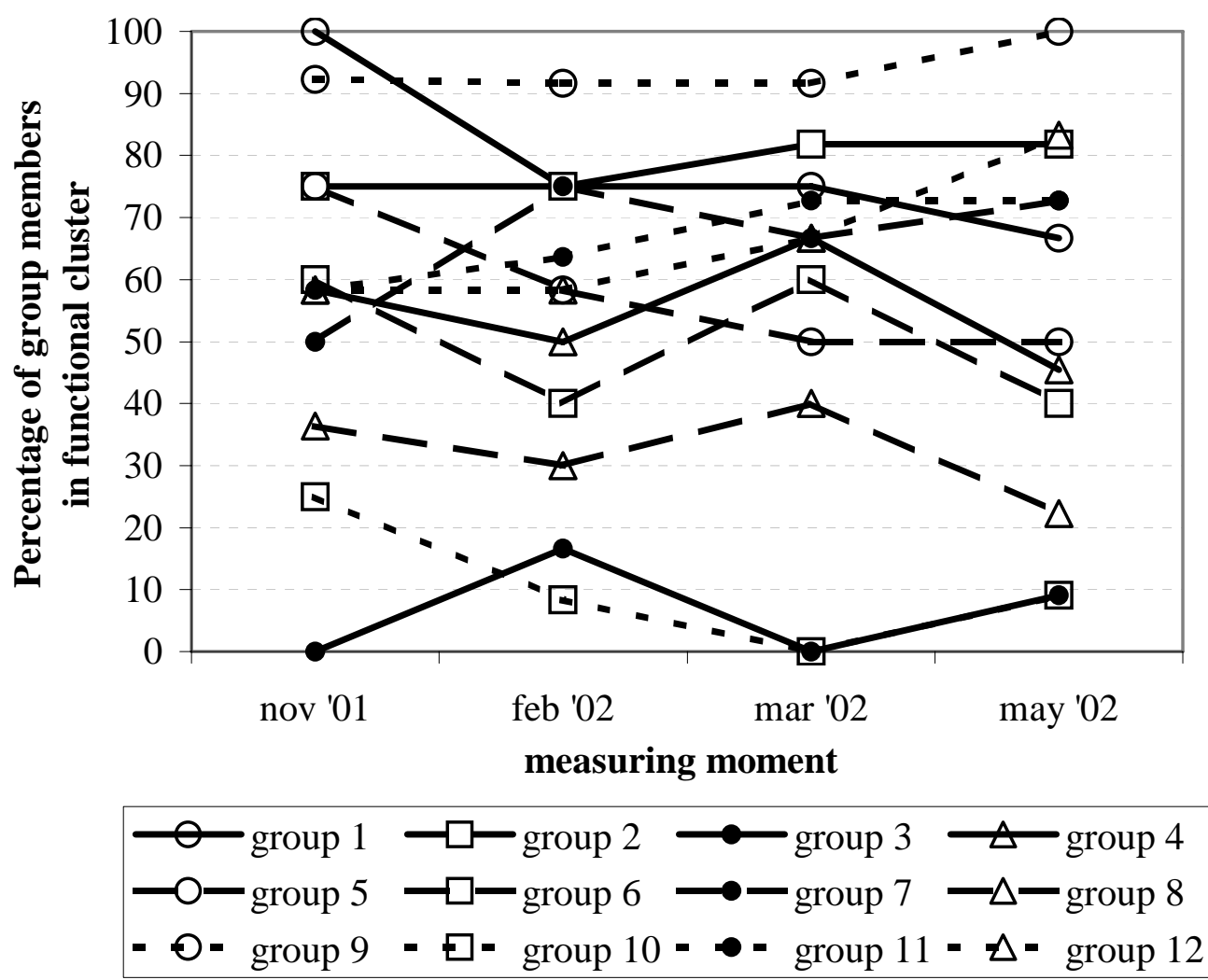

Figure 1: The percentage of group members in the functional cluster at the four measuring moments. 
FIGURE 2

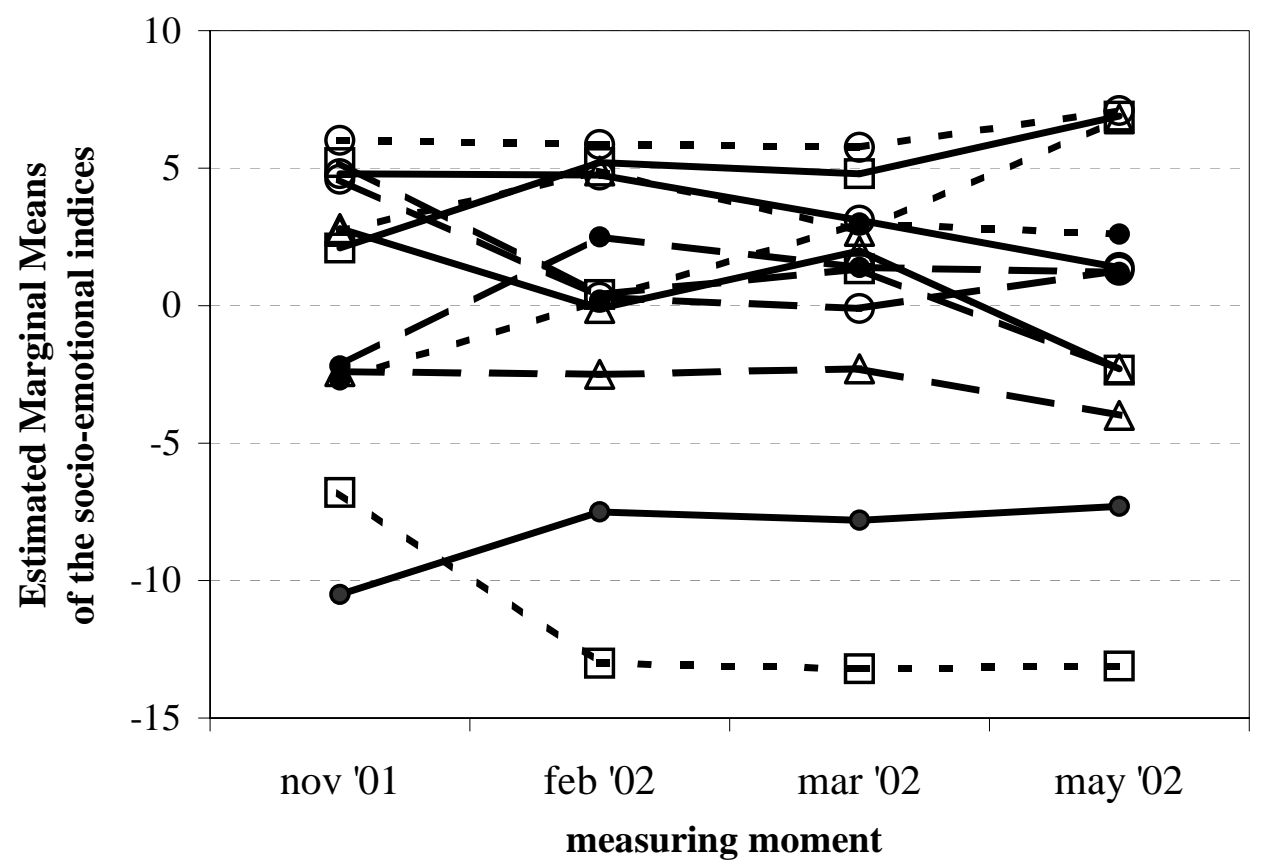

- group $1 \longrightarrow$ group $2 \rightarrow$ group $3 \rightarrow \Delta$ group 4 $\longrightarrow$ - group $5 \longrightarrow \square$ group $6 \longrightarrow$-group $7-\Delta$-group 8 - 0 - group 9 - $\boxminus$ - group 10 - ๑ - group $11-\Delta$ - group 12

Figure 2. Estimated marginal means of the socio-emotional indices for the twelve groups at the four measurement moments. 